\title{
Type I allergic reaction to rituximab upon first lifetime exposure: a case report
}

\author{
V. Polito ${ }^{1}$, A. Barbacki ${ }^{1}$ and G. Isabwe ${ }^{2^{*}}$ (D)
}

\begin{abstract} exposure, she experienced immediate anaphylaxis 30 min into infusion. potentially life-threatening. Cytokine reaction, Type I reaction

\section{Background}

Rituximab is a chimeric monoclonal antibody (MAB), which is approximately $65 \%$ human, the remainder being mouse epitope. It binds to the CD20 antigen on B cells and is primarily used in the treatment of autoimmune disorders and malignancies [1]. We describe an unusual presentation of rituximab hypersensitivity.
\end{abstract}

Background: While drug reactions to rituximab have been commonly reported in the literature, a type I allergic reaction to rituximab after first lifetime exposure has never been reported.

Case presentation: We describe a case of a 58-year-old female patient who received rituximab for the first time for treatment of rheumatoid arthritis. She developed symptoms immediately after infusion, however presented 11 days after drug exposure with cyclical anaphylaxis-like reaction requiring multiple doses of epinephrine. On second

Conclusion: Our case illustrates the importance of heightened awareness by physicians that type I lgE-mediated reactions after first exposure to monoclonal antibodies such as rituximab are possible, and if unrecognized, could be

Keywords: Rituximab, Monoclonal antibody, MAB, Hypersensitivity, IgE, Anaphylaxis, Drug allergy, Infusion reaction,

\section{Case presentation}

Our patient is a 58-year-old woman known for rheumatoid arthritis, depression, and migraines. Her medications include bupropion and low-dose prednisone (5-10 mg [mg] daily). She has no personal or family history of allergy or urticaria. She previously failed treatment for her rheumatoid arthritis with methotrexate, tocilizumab, and tofacitinib. During her first infusion of

*Correspondence: ghislaine.isabwe@mcgill.ca

2 Division of Allergy and Clinical Immunology, Department of Medicine, McGill University Health Centre, McGill University, Montreal, QC, Canada

Full list of author information is available at the end of the article rituximab (administered over $4 \mathrm{~h}$ ), she developed fatigue and a migraine which persisted for 4 days post-infusion. On day 2 post-rituximab, she also developed 1 day of throat pain. On day 10, the patient had transient diffuse scalp pruritus. On day 11, she developed pruritus which developed into urticaria followed by face and tongue angioedema and throat tightening. On presentation to the emergency room (ER), she was tachycardic (at 123) with otherwise normal vital signs and normal physical exam. She was given famotidine $20 \mathrm{mg}$ and methylprednisolone $80 \mathrm{mg}$ intravenously (IV), and diphenhydramine $50 \mathrm{mg}$ orally (PO). Despite initial improvement of her symptoms, the patient's urticaria, angioedema, and chest tightness with wheezing re-occurred. She was given a dose of epinephrine $0.5 \mathrm{mg}$ IM. The patient remained in the ER for over $48 \mathrm{~h}$ with recurrences of her symptoms necessitating IM epinephrine a total of three times. Repeated vital signs were normal other than intermittent tachycardia (100-125). Bloodwork showed a C-reactive protein (CRP) of $144.14 \mathrm{mg} / \mathrm{L}$ (liter), a tryptase of $11.9 \mu \mathrm{g}$ (microgram)/L done $15 \mathrm{~h}$ after arrival, and a white blood 
cell count of 15.60. Once stable, she was discharged home with cetirizine $10 \mathrm{mg}$ PO daily as needed.

Twenty-four hours after discharge, the patient returned with subjective symptoms of pruritus and body aches. She had received epinephrine IM in ambulance. Bloodwork showed a CRP of $52.96 \mathrm{mg} / \mathrm{L}$ and a tryptase of $3.4 \mu \mathrm{g} / \mathrm{L}$. There was no objective evidence of ongoing reaction. She was discharged home with a PO prednisone taper. She was subsequently seen in the allergy clinic and at that time, the reaction was thought to be unlikely secondary to Rituximab.

On day 26, she received her second dose of Rituximab in an outpatient clinic. She was pre-medicated with acetaminophen $650 \mathrm{mg} \mathrm{PO}$, diphenhydramine $50 \mathrm{mg}$ IV and methylprednisolone $125 \mathrm{mg}$ IV. Thirty minutes after initiation of the infusion, the patient developed symptoms of chest pain and throat tightness. Objectively, she was found to have urticaria at the infusion site and became hypotensive with a systolic blood pressure of 94 from 140 , along with hypoxia requiring $5 \mathrm{~L} / \mathrm{min}$ oxygen via nasal prong to maintain a saturation of $95 \%$. The rest of her vital signs were normal. She was given epinephrine IM as well as diphenhydramine $25 \mathrm{mg}$ IV and transferred to ER. In the ambulance, her oxygen requirement and hypotension quickly resolved post-administration of epinephrine. Upon arrival she was asymptomatic, with normal vital signs. Her CRP was $3.11 \mathrm{mg} / \mathrm{L}$ and tryptase was $5.2 \mu \mathrm{g} / \mathrm{L}$. After observation for $12 \mathrm{~h}$, she was discharged on PO prednisone with a slower taper to home dose, and was referred back to the allergy clinic.

Rituximab skin prick test was negative at a concentration of $10 \mathrm{mg} / \mathrm{mL}$. Intradermal skin testing was started at 1:1000 dilution $(0.01 \mathrm{mg} / \mathrm{mL})$ and quickly became positive with a wheal of $6 \mathrm{~mm}$ and flare of $20 \mathrm{~mm}$. Saline control was negative. Histamine control showed a wheal of $5 \mathrm{~mm}$.

\section{Discussion and conclusion}

Reports of mild infusion reactions with rituximab are common, particularly during first infusions. Molecular studies seem to suggest a key role for complement system activation for infusion reaction [2]. Common symptoms include flushing, fever, rigors, and malaise. They improve with symptomatic treatment (anti-pyretic, anti-emetic medications, steroids) or slower infusion, and tend not to recur. Cytokine-mediated reactions can present with similar symptoms, however unlike infusion reactions, they can persist many days post-infusion, do not respond to symptomatic treatment, and will recur with subsequent infusions [3, 4]. Type I reactions to Rituximab are frequent and both IgE and nonIgE mediated. Symptoms may involve multiple organ systems. Skin-testing to Rituximab is one way to help confirm IgE-mediated allergy [5, 6].

In this case, since the patient's symptoms persisted more than $24 \mathrm{~h}$ post-infusion, we question a potential cytokine-release reaction initially. On day 11 after initial exposure to rituximab, the patient presented with urticaria and angioedema which can be consistent with Type I reaction versus other unrelated condition such as spontaneous urticaria/angioedema. However, we hypothesize that, given the half-life of rituximab in the blood for rheumatoid arthritis is approximately 18-23 days [7], circulating antigens in the bloodstream caused the patient to develop antibodies to rituximab and convert from a cytokine-mediated reaction to a Type I reaction. In retrospect, this theory was supported by her elevated tryptase level of $11.9 \mu \mathrm{g} / \mathrm{L}$ (from baseline tryptase of $3.4 \mu \mathrm{g} / \mathrm{L}$, using formula $1.2 \times$ baseline tryptase $+2 \mu \mathrm{g} / \mathrm{L}$ ) [8]. The persistence of circulating antigens in her bloodstream may also explain why the patient had a cyclical nature to her symptoms requiring multiple doses of epinephrine. Given it was the first exposure to rituximab, and given alternative possible explanations to her first presentation (for example, spontaneous urticaria/angioedema), the allergy clinic initially thought her first reaction was unrelated to rituximab. However, her symptoms after second exposure along with subsequent evidence of positive skin testing confirmed a true type I hypersensitivity to rituximab. As well, there was no history and no recurrence of urticaria/ angioedema outside of exposure to rituximab.

Another potential question may be cross-reactivity between rituximab and the patient's previous MAB treatment with tocilizumab due to the mouse epitope in both. We do not think this was the case since the patient received doses of tocilizumab on multiple occasions in the past without any reaction. The literature also supports that cross-reactivity is unlikely, given that there are no reported cases of proven anaphylaxis after first exposure due to cross-reactivity between MABs [9]. In fact, there are reports of safe administration of rituximab after anaphylaxis to obinutuzumab, which belongs to the same class of MAB as tocilizumab and is over $95 \%$ humanized $[1,10]$.

We have described an unusual case of cytokinemediated reaction to rituximab after a first infusion, which subsequently converted to a type I IgE-mediated reaction after only one infusion of rituximab. To our knowledge, this is the first reported case of this type of reaction to rituximab. The patient and her treating team were made aware that desensitization for future infusions could be pursued, however, they decided to opt for an alternative treatment regimen. 


\section{Abbreviations}

MAB: Monoclonal antibody; mg: Milligram; IM: Intramuscularly; IV: Intravenously; PO: Orally; CRP: C-reactive protein; L: Liter; $\mu$ g: Microgram; ER: Emergency room.

\section{Acknowledgements}

Not applicable.

\section{Authors' contributions}

All authors contributed to the writing, editing the manuscript. All authors read and approved the final manuscript.

\section{Funding}

No relevant funding to declare.

\section{Availability of data and materials}

Not applicable.

\section{Ethics approval and consent to participate}

Not applicable.

\section{Consent for publication}

Not applicable.

\section{Competing interests}

The authors declare that they have no competing interests.

\section{Author details}

${ }^{1}$ McGill University, Montreal, QC, Canada. ${ }^{2}$ Division of Allergy and Clinical Immunology, Department of Medicine, McGill University Health Centre, McGill University, Montreal, QC, Canada.

Received: 4 April 2020 Accepted: 4 June 2020

Published online: 26 June 2020

\section{References}

1. Buss NA, Henderson SJ, Mcfarlane M, Shenton JM, Haan LD. Monoclonal antibody therapeutics: history and future. Curr Opin Pharmacol. 2012:12(5):615-22.
2. Kolk LEVD, Grillo-Lopez AJ, Baars JW, Hack CE, Oers MHJV. Complement activation plays a key role in the side-effects of rituximab treatment. $\mathrm{Br} J$ Haematol. 2001;115(4):807-11.

3. Isabwe GAC, Neuer MG, Sanchez LDLV, Lynch D-M, Marquis K, Castells M. Hypersensitivity reactions to therapeutic monoclonal antibodies: phenotypes and endotypes. J Allergy Clin Immunol. 2018;142(1):159-70.

4. Ornust SV, Lamb HM, Barman Balfour JA. Rituximab. Drugs. 1999;58(1):79-88.

5. Bugelski PJ, Achuthanandam R, Capocasale RJ, Treacy G, Bouman-Thio E. Monoclonal antibody-induced cytokine-release syndrome. Expert Rev Clin Immunol. 2009:5(5):499-521.

6. Kimby E. Tolerability and safety of rituximab (MabThera $\left.{ }^{\circledR}\right)$. Cancer Treat Rev. 2005;31(6):456-73.

7. $\mathrm{Ng} \mathrm{CM}$, Bruno R, Combs D, Davies B. Population pharmacokinetics of rituximab (Anti-CD20 Monoclonal Antibody) in rheumatoid arthritis patients during a phase II clinical trial. J Clin Pharmacol. 2005;45(7):792-801.

8. Valent P, Bonadonna P, Hartmann K, Broesby-Olsen S, Brockow K, Butterfield $\mathrm{JH}$, et al. Why the $20 \% 2$ tryptase formula is a diagnostic gold standard for severe systemic mast cell activation and mast cell activation syndrome. Int Arch Allergy Immunol. 2019;180(1):44-51.

9. Maneiro JR, Salgado E, Gomez-Reino JJ. Immunogenicity of monoclonal antibodies against tumor necrosis factor used in chronic immunemediated inflammatory conditions. Clin Gov Int J. 2013;173:1416-28.

10. Salomon-Perzyński A, Końska A, Zawirska D, Lech-Marańda E, Jamroziak K. Safe administration of rituximab in patients with chronic lymphocytic leukemia and a history of obinutuzumab-associated anaphylaxis. Polish Archiv Intern Med. 2018;128(7-8):494-5

\section{Publisher's Note}

Springer Nature remains neutral with regard to jurisdictional claims in published maps and institutional affiliations.
Ready to submit your research? Choose BMC and benefit from

- fast, convenient online submission

- thorough peer review by experienced researchers in your field

- rapid publication on acceptance

- support for research data, including large and complex data types

- gold Open Access which fosters wider collaboration and increased citations

- maximum visibility for your research: over $100 \mathrm{M}$ website views per year

At $\mathrm{BMC}$, research is always in progress.

Learn more biomedcentral.com/submissions 